\title{
Study on the Social Impact of Shantang in Chaoshan Area
}

\author{
Enyu Shi \\ School of Humanities and Law, South China Agricultural University, Guangzhou, 510642, China
}

Keywords: Charity, Chaoshan, Society history, Influence

\begin{abstract}
There is a distinctive local characteristics of the charity in Chaoshan area . Today, the charities are still active in the area of society. This paper tries to explore their relations with regional society and local government so as to provides the beneficial reference for charities and other civil society organizations development through the review related history of charity in Chaoshan area its effect in Chaoshan society such a "public domain" .
\end{abstract}

\section{Introduction}

Charity association and charity hall are kind of important folk organization in China formed during the Ming and Qing Dynasties . Since the Ming and Qing Dynasties, the Charitable institutions exist for a long time in the regional society and play an important role. In my hometown Chaozhou Shantou area, there are traditional sense of shantang and another different shantang . This colorful kind of folk charity with folk belief , similar to the charity that the American scholar Rowe said "charity Temple appearance" , the most of them worship founding master Song Feng, which are the major object studied in this paper .

\section{Charity organization}

This section will talk about the kind of characteristic of Chaoshan area charities organization, through its organization form to explain its unique. This section intends to study the Shantang from two aspects: the found of the shantang and its economic sources ..

\section{The establishment of Shantang}

The start-up of the Shantang should be traced back to the creation of the Southern Song Dynasty ancient Tang De Chaoyang peace.According to the historical data, the ancient church was originally founded to revered peak founder mark Zufeng to the commemoration of the bridge of merit, rather than a charity organization carrier. As it turned into a charity organization, it seems that there is no proof .After study of Chaoshan, most of the shantang were founded in the latter half of the Guangxu in Qing dynasty. According to the local chronicles, during this period, frequent natural disasters in Chaoshan area, and thus lead to the plague, cholera epidemic. At the same time, outside and wolf tiger infestation. This background can be regarded as the objective demand of the society of the emergence of Chaoshan area.

According to the point of view of the social and historical background. At that time, China was in the domestic trouble and foreign invasion, the turbulent political situation, the official of some of the hardships of the people was superabundant. According to book " the study of the history of Chinese charitable institutions - prodrome” written by Japanese writer Fuma Susumu , , in the traditional sense of sin, after Ching Yong Zheng 2002 (1724) issued an imperial edict, due to local officials on the edict of wrong interpretation, making in the country gradually appeared a " officially operation of the Shantang and corvee of and charity."

Since then the officially operation of the charity was increasingly serious, its business charity amounts required were forced to apportion the people, at this time of charity seems to in essence amounts to corvee. In this way, people produced a kind of resentment, resistance to the traditional psychological type came out Shantang . Therefore, the traditional charities in the community was difficult to play its role, organization in the society of the charity have needs, and traditional charities can not play its role. Folk spontaneous organizations replaced its role, which contributed to the new charities in Chaoshan area . 


\section{The organizational structure of the Shantang}

The organizational structure of the Shantang early was organized by the people who was elected from the members of the society .After the continuous improvement came out the board of directors and the board system, and retained to the present. Today, the organizational structure of the Shantang in Chaoshan area is still board with the Council, and provided with a plurality of departments, carrying out their duties. When the Shantou charity established, it was unified management by 17 members elected from the member assembly. It changed to the board of directors with 17 directors and 1 chairman in the Republic of China for twenty-eight years (1939).In the Republic of China 30 years (1941, Shantou has occupied), in accordance with the "people's organizations restructuring program for directors and supervisors", the Shantou City Government Bureau of social established a supervision meeting composed of 17 directors 13 supervisors. Under the supervision meeting they had financial, general affairs, education, relief, medical and religious rituals, communication, investigation, audit supervision, the director of the supervision work part-time for a term of one year. Other Shantangs' situation in Chaoshan were the same .

The author found a phenomenon in the personnel composition through research to some Shantang establishment: the start-up of the Shantang was sponsored by the lower ordinary people; but different from traditional charities, when these local charities developed to a certain degree, industry and business people would join and play a role. We seem to look at it this way, with the development of modern industry and commerce, industrial and commercial sectors as the new emerging class to seek a firm foothold in the community playing a role in the platform and to combat with the old class .That' $s$ why local charities in the Chaozhou Shantou area was one of the platforms they were seeking.

The members of the Shantang are generally composed by the general public, people need to pay a certain amount of fund to be friends of the agency. Why are these ordinary people so eager to become a social friend? On the one hand ,the members are active worship kindness ;on the other hand, according to the rules and regulations of the most Shantangs, members in some charity activities enjoy a right of priority generally means that sometimes themselves or their relatives and friends have the priority in life rescue. We can see that the ordinary people in the ancient, would also seek help from the Shantang if they failed to guarantee in life, .

\section{The economic source of the Shantang}

It need a lot of money to maintain the Shantang since the date of its creation to the daily operation. This is mainly due to the donation of the good people. In these good people's contributions, not limited to money, but also included in the donation of the land.

On the other hand, if you join in the Shantang (or charity) which means you have been a member. Refer to the rules and regulations, members required to pay a certain amount fund before joining The past regulations are not well documented, but it seems that we can also refer to this system speculates that it is an important source of income to maintain daily operation of Shantang.

It is with a source of income to maintain the daily operation of theShantang that the Shantang can commit to the charitable sector within the community and taking participation to the area of daily affairs.

\section{The main activities of the Shantang}

The main charity activities in the Shantang can be considered from two aspects: one is humanistic care, one is in the area of public construction.

\section{Humanistic care}

Chaoshan charity hall in humanistic care, the most important is buried skull. In eleven years (1922), the Chaoshan area occurred a massive storm, known as the "eight - two" typhoon. According to the records of "Chaozhou annals":"...... The victims of the disaster, such as the twenty-six thousand nine hundred and ninety-six dead in Chenghai......, a total of thirty-four thousand five hundred people. Houses into ruins, and the mountain with my corpse everywhere more than the product and still not clear view". At the time of Chaozhou intended to pay a lot of manpower and material resources, bury 
the corpses of dead comrades. Chaozhou Guangji, Shou Ming twenty LST has rushed to bury dead outside the sand. Due to the duration of heat, rotting corpses, vulnerable to infection, but the lst to collect the buried team still face difficulties, time-consuming more than in January will bones are buried is completed. During the Anti Japanese War, the Chaoshan area also often to the battlefield LST martyrs hide my bones.

Charity has always been the traditional free medical service, it is also an important one of the charity, benefit the people of those few. As the period of the Republic of Chaozhou Ji'an charities, often hired a number of famous doctor clinic. According to the statistics, there are four or five people visiting each doctor, donated drugs in three thousand oceans around a month. Of 38 years (1949), 16 September Malaya "Chaozhou Xiang Xun newspaper reported:" Chao Cheng Nan Ke Makotoasudo in July medicine donated medicine statistics: Outpatient three thousand five hundred and eighty-eight people (Times), the door of the consulting person 61 people (Times). " Founder of the folk charity, to raise funds, has long been in favor of people, it is rare. In addition, charities also often routine elderly and disabled, orphans and the poor and other acts of kindness.

\section{The organization and construction of public facilities in the region}

The lst charity, including organization and construction of basic facilities, in the public domain, such as bridges, road building, founder of the hospital, and civil organizations fire team etc..

Dafeng is the earliest record of events, the repair and the issue of Pingqiao. Later the lst, in Dafeng, will repair the bridge as a major activity of road construction. Such as just mentioned above the Chaoshan "eight - second" big storm, Shantou deliberately LST a relief activities is "repair Han and Rongjiang coast is tide impulse break burst prevention, and the establishment of the tau Yuting, and Cheng is cited Deng village to build the bridge."

Chaoan um town Taihe charities have compatriots and good faith donated jointly founded the Taihe hospital, hospital, founded the eastern first You Shantang makes many people benefited from around, enjoy a high reputation. But in 1939, due to the Japanese invasion, lst church site and hospital were occupied, to rescue injured people, may not have been relocated to Cai Tang Zhen Jin Sha Xiang, continue to carry out charity.

Chaoshan area local charities and some important building initiatives is the organization folk fire brigade (or hose Bureau) was established, bear the local fire services. For example, the society of the fire brigade was first established, where there is no fire department official, people can only rely on their own fire. So benevolent society serves as a local fire mission, set up their own fire team, into the regional society inside a small fire power. As before liberation, Chaozhou City have 21 branch of compulsory fire team, of which the vast majority of dubbed LST name, apparently to charities established.

\section{The social impact of the Shantang}

In the Chaozhou and Shantou area, effect of Shantang to a regional society is great. This section try from two aspects of the government and the people, to explore the social and cultural functions of Shantang.

\section{Between Shantang and the government}

It seems to have a subtle relationship between the government and charity. When the local social encounter some problems , they need the government for some relief help, local charities tend to play a certain role on behalf of the government when the inability of the government to distraction. At the same time, the number of the traditional charity established by government is limited, only in the centre of city and county. This is not conducive to its wide range of charity. Chaoshan local charities are different . These charities set up by the people themselves, the operation is more flexible, and the scale can be big or small, so it is more able to facilitate its in-depth rural areas to carry out their philanthropy. Even some charities still in the village set up the branch, the branch of some scale is indeed small, but really can make the some charity implemented, to benefit the people. Thus, we seem to be able to say that local charities in Chaoshan area, in fact, is a supplement to the government charity, a kind of extension. And local opinion, these charities in society, the role played in people, is greater than the government run the traditional charities. 
Why the traditional sense of the Shantang playing a role as a history, however, Chaoshan local charities still active in the social area due to the various features of the Chaozhou and Shantou area. Local charities makes it possible to really play a role in regional society, the charity will be implemented. They have a tremendous role in regional society, so that they retained, continue to play a role. At the same time, this problem is also related to local charities and Chaozhou Master Dafeng and other gods worship of folk belief. More important ,Shantang of Chaoshan area, but also the ties of solidarity with the overseas compatriots, therefore, by the support of the government.

\section{Between Shantang and the people}

Ms. Liang Qizi in the "charity and civilizing: of the Ming and Qing Dynasties charitable organizations," a Book opening had mentioned: "(Shantang ,charity institutes ) is not simply to solve the social poor problem, in fact they also can not solve these problems, but by applying good to try to rebuild social order." Although above views in the Chaozhou and Shantou area may not be very accurate , one thing for sure is "try reforming social order", simply speaking to emphasize a advised people to do good education function.

There is a special role of the public charity, that is autonomous consciousness of a culture for the people. We look at the modern set up the local charities, at the time of its creation, with a populace autonomous means inside. Thirteen years of the Republic of China (1924), the national government has ordered the destruction of the temple, the abolition of yinsi.

In the seventeen years (1928) around the Chaoshan began to perform, when the dedicated to high peak founder charities are also presented in which will be abrogated. Resulted in Chaoshan area joint argue, when on behalf of the Shantang held plenary meeting, list Shantang should be preserved. In the eighteenth year of the Republic of the national government's Ministry of the interior of a document in the legitimacy of the Shantang conclusions, "real and the temple prostitution, gods and spirits, Wu wish like different Yang Hou separately Guangdong Department of Civil Affairs turn to protection, in admiration, and Zhao teach advised", making Chaoshan area Shantang recognized, also makes the patriarch Feng beliefs legitimizing is autonomous consciousness of the people a good embodiment of.

\section{Other discussions}

The charity organization like Chaozhou shantang with a distinctive religious folk is a special case of the folk charity China. It should be said that in times of national calamity, Chaozhou shantang for the social stability in the region, to solve all the social problems that existed at the time plays a positive function. In today's era, Chaozhou chantang also plays a positive role with great practical significance.Shantang culture makes big sense in maintaining local social stability, which should be vigorously promoted. We should strengthen the research of Chaozhou charity culture, so as to provide useful reference for the development of other non-governmental organizations and charities.

\section{References}

[1] Rao Zongyi compile. Chaozhou Record , Great Event Record. Event - Chaozhou City Office 2000.

[2] Fuma Susumu. The study of the history of Chinese charitable institutions - prodrome. The commercial press.2005.

[3] Liang Qizi. Doing good and moralizing: Enlightenment of the Ming and Qing Dynasties" Hebei people's education press, 2001.

[4] Weng Zhaorong Xu Zhensheng. Shantang charity summarize of Chaozhou before liberation. Literary and History of the Shengping (first series) - Chaoshan shantang album.

[5] Strict Management Agency. Literary and history of the Sheng ping (first series) - Chaoshan shantang album. 